University of Nebraska - Lincoln

DigitalCommons@University of Nebraska - Lincoln

Nonsurgical fertility control for managing free-roaming dog populations: A review of products and criteria for field applications

\author{
Giovanna Massei \\ Food and Environment Research Agency, gmassei@botstiber.org \\ Lowell A. Miller \\ USDA/APHIS/Wildlife Services' National Wildlife Research Center, Fort Collins, CO, \\ lowell.a.miller@aphis.usda.gov
}

Follow this and additional works at: https://digitalcommons.unl.edu/icwdm_usdanwrc

Massei, Giovanna and Miller, Lowell A., "Nonsurgical fertility control for managing free-roaming dog populations: A review of products and criteria for field applications" (2013). USDA Wildlife Services - Staff Publications. 1234.

https://digitalcommons.unl.edu/icwdm_usdanwrc/1234

This Article is brought to you for free and open access by the U.S. Department of Agriculture: Animal and Plant Health Inspection Service at DigitalCommons@University of Nebraska - Lincoln. It has been accepted for inclusion in USDA Wildlife Services - Staff Publications by an authorized administrator of DigitalCommons@University of Nebraska - Lincoln. 
Review

\title{
Nonsurgical fertility control for managing free-roaming dog populations: A review of products and criteria for field applications
}

\author{
Giovanna Massei ${ }^{\mathrm{a}, *}$, Lowell A. Miller ${ }^{\mathrm{b}}$ \\ ${ }^{a}$ National Wildlife Management Centre, Animal Health and Veterinary Laboratories Agency, Sand Hutton, York YO26 5LE, UK \\ ${ }^{\mathrm{b}}$ US Department of Agriculture Animal and Plant Health Inspection Service, National Wildlife Research Center, 4101 LaPorte Avenue, CO 80521, Fort Collins, \\ Colorado, USA
}

\section{A R T I C L E I N F O}

\section{Article history:}

Received 24 January 2013

Received in revised form 17 July 2013

Accepted 19 July 2013

\section{Keywords:}

\section{Contraception}

Dog population management

Fertility inhibitors

GnRH agonists

Immunocontraception

Sterilants

\begin{abstract}
A B S T R A C T
About $75 \%$ of dogs worldwide are free to roam and reproduce, thus creating locally overabundant populations. Problems caused by roaming dogs include diseases transmitted to livestock and humans, predation on livestock, attacks on humans, road traffic accidents, and nuisance behavior. Nonsurgical fertility control is increasingly advocated as more costeffective than surgical sterilization to manage dog populations and their impact. The aims of this review were to 1) analyze trends in numbers of scientific publications on nonsurgical fertility control for dogs; 2) illustrate the spectrum of fertility inhibitors available for dogs; 3 ) examine how differences between confined and free-roaming dogs might affect the choice of fertility inhibitors to be used in dog population management; and 4) provide a framework of criteria to guide decisions regarding the use of nonsurgical fertility control for dog population management. The results showed that the 117 articles published between 1982 and 2011 focussed on long-term hormonal contraceptives, such as gonadotropin-releasing hormone agonists, immunocontraceptives, and male chemical sterilants. The number of articles published biennially increased from one to five papers produced in the early 1980 s to 10 to 20 in the past decade. Differences between confined dogs and free-roaming dogs include reproduction and survival as well as social expectations regarding the duration of infertility, the costs of sterilization, and the responsibilities for meeting these costs. These differences are likely to dictate which fertility inhibitors will be used for confined or free-roaming dogs. The criteria regarding the use of fertility control for dog population management, presented as a decision tree, covered social acceptance, animal welfare, effectiveness, legal compliance, feasibility, and sustainability. The review concluded that the main challenges for the future are evaluating the feasibility, effectiveness, sustainability, and effects of mass nonsurgical sterilization campaigns on dog population size and impact as well as integrating nonsurgical fertility control with disease vaccination and public education programs.
\end{abstract}

(C) 2013 Published by Elsevier Inc.

\section{Introduction}

The global dog population is estimated to be around 700 million [1]. National and international organizations working on dog population management and welfare often classify dogs in the following categories, according to

\footnotetext{
* Corresponding author. Tel.: +44 1904 462076; fax: +44 1904462111. E-mail address: giovanna.massei@ahvla.gsi.gov.uk (G. Massei).
}

ownership and degree of confinement: 1) owned and permanently confined within household premises; 2) owned by a single household but free to roam; 3) "community owned," with several households or people providing food and shelter but free to roam; or 4) ownerless and free-roaming. About 75\% of the worldwide dogs, often referred to as stray, are free to roam and reproduce [2]. This creates locally overabundant populations of animals that are often in poor health and have a high turnover because of low survival rates. 
Problems caused by free-roaming dogs include diseases transmitted to livestock and humans, predation on livestock, bites, road traffic accidents, and nuisance behavior such as barking and soiling [3,4]. Although some studies found that the majority of dog bites are due to dogs that are owned by or known to the victims rather than to strays [5-7], free-roaming dogs share some of the responsibility for bites [4]. For instance in Samoa, 56\% of bites occurred in a public place [6]; in Bangalore (India), 64\% of dog bites were associated with stray dogs [8]. Among the zoonoses, rabies is of particular concern for humans and livestock: dogs are responsible for $>90 \%$ of the estimated 55,000 human deaths and for the millions of people that each year receive postexposure prophylaxis following a bite [9]. The majority of deaths and postbite vaccinations occur in Asian and African countries, which can barely afford this economic burden [9]. Dogs also pose serious threats to wildlife and biodiversity as predators, competitors, transmitters of disease, and by interbreeding with native species $[1,10]$.

Traditional efforts to mitigate problems caused by freeroaming dog populations rely on public education, disease vaccination, and population management, the latter carried out through lethal control or through fertility control. Lethal control is increasingly opposed by local communities, nongovernmental agencies, and animal welfare organizations because of its lack of humaneness and effectiveness and because of the impact of toxicants on the environment and on nontarget species [11,12]. Culling has also a social impact, because many free-roaming dogs do have owners that will oppose indiscriminate killing. In addition, people may be against culling for religious beliefs [13,14]; for instance, Buddhism and Hinduism oppose animal slaughtering [13].

Dog population management has focused recently on surgical sterilization, often provided as subsidized or free services to dog owners or through catch, neuter, and release of free-roaming dogs. Although surgical sterilization is more socially acceptable than culling, it is relatively expensive because of the use of drugs, specialized staff, and facilities, and has potential welfare risks because of the use of anesthetics [15-17]. In addition, some dog owners are opposed to surgical sterilization, citing compassion, unnecessary procedure, cost, and behavioral changes as reasons against this method $[15,18]$.

Contraceptives and sterilants (hereafter referred to as fertility inhibitors or fertility control agents unless otherwise specified) could provide a cost-effective, humane alternative to surgical sterilization. In recent years, the potential market for these drugs and a growing public interest in alternatives to surgical sterilization for companion animals, wildlife, and livestock have promoted investments into the development of fertility inhibitors. Nonsurgical fertility control is increasingly advocated for the resolution of human-wildlife conflicts $[19,20]$ and as alternatives to surgical sterilization in livestock, zoo, and companion animals [21]. In companion animals, fertility inhibitors are used for preventing reproduction, suppressing nuisance behavior such as spraying, roaming, and aggressiveness and for treating medical conditions [22,23]. Nonsurgical sterilization of free-roaming dogs has the potential to be more costeffective than surgical sterilization in reducing the size and impact of dog populations as many more animals can be treated compared with the numbers that can be neutered or spayed per unit time [16,24]. The first part of this review analyzes trends in the number of scientific publications on nonsurgical sterilization for dogs, used as an indicator of public growing interest in this field. The second part illustrates fertility inhibitors currently available or widely tested on wildlife and on companion animals.

Previous reviews of fertility inhibitors for companion animals paid relatively little attention to the differences between confined and free-roaming dogs in terms of reproduction, survival, or owner and/or community expectations regarding use and outcomes of fertility control. The third part of the review discusses how these differences might affect the choice of drugs used to control fertility in dogs, with particular focus on fertility inhibitors that are likely to be employed for large-scale field applications. The fourth part of the review examines nonsurgical sterilization in the wider context of dog population management and provided a framework of criteria to guide decisions in this area.

\section{Trends in numbers of scientific publications on nonsurgical sterilization for dogs}

To analyze trends in numbers of scientific publications on nonsurgical sterilization for dogs in the past 30 years, we used a text search approach on four databases: BIOSIS, CAB Abstracts, Zoological Records, and Medline, all accessed on October 12, 2012. We used the following keywords in the title or the abstract of publications: "dog," "fertility control," "fertility inhibition/inhibitor," "immunocontraception/immunocontraceptive," "reproductive inhibition/inhibitor," “contraception/contraceptive," "sterilization." The results of database searches were used to obtain the following data: 1) number of articles published per year; 2) number of gender-specific applications of fertility inhibitors (i.e., females only, males only, or both); 3 ) type of study, classified as in vivo, in vitro, or review or model; and 4) type of contraceptive, divided into "male sterilant" (including only drugs delivered through testicular injection), "immunocontraceptives," "GnRH agonists and antagonists," "synthetic progestins," and "other." Reviews were included only if they explicitly mentioned dogs. Only articles that referred explicitly to fertility inhibitors for dogs were included; publications aimed at evaluating sterilants and contraceptives for their therapeutic uses were not included. For ease of presentation, the number of articles published every 2 years was calculated.

The results showed that 117 articles were published between 1982 and 2011. The trend indicated that the number of publications increased considerably from one to five articles published biennially in the early 1980s to mid1990 s to 10 to 20 in the most recent decade (Fig. 1).

Possible reasons for the increase include: 1) progress in the elucidation of the molecular mechanisms regulating fertility in dogs; 2) availability of new technologies, such as slow-release implants, that widened the spectrum of applications for fertility control in dogs; 3 ) pressure from the public and from animal welfare organizations to develop alternative methods to lethal control or to surgical sterilization; and 4) advancements in several, parallel fields, such 


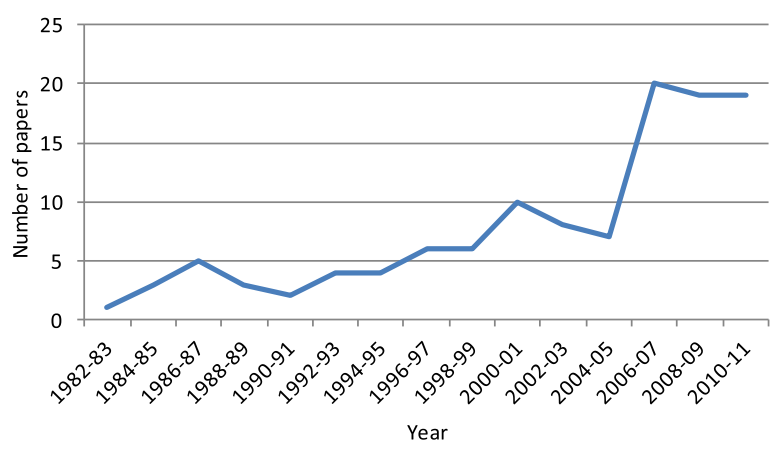

Fig. 1. Number of biennial publications containing the defined search terms on fertility inhibitors for dogs.

as contraceptives developed for livestock and wildlife $[22,25,26]$.

Out of the 117 articles, $62 \%(n=73)$ referred to in vivo and in vitro empirical studies and the remaining to reviews or models. Of the 64 in vivo studies, $51.5 \%(n=33)$ were carried out on females only, $47 \%(n=30)$ on males only, and one study (1.5\%) on both genders. Fertility inhibitors used in the in vivo studies were $16 \%(\mathrm{n}=10)$ male sterilants, $17 \%$ $(\mathrm{n}=11)$ immunocontraceptives, $56 \%(\mathrm{n}=36) \mathrm{GnRH}$ agonists and antagonists, $11 \%(\mathrm{n}=7)$ synthetic progestins $(\mathrm{n}=$ $4)$ and other contraceptives $(n=3)$.

\section{Contraceptives and sterilants}

Chemical fertility control can be achieved through contraception, which prevents the birth of offspring but maintains fertility or by sterilization, which renders animals infertile [27,28]. GnRH is one target for fertility inhibitors. GnRH controls the release of the pituitary gonadotropins, LH and FSH, which in turn control the production of sex hormones and ultimately ovulation, spermatogenesis, and sexual behavior. In females, a further target for contraception is the zona pellucida (ZP), a group of proteins that surrounds the ovulated egg and allows species-specific sperm recognition and fertilization. In males, sterilization can also be achieved by chemicals that cause testicular sclerosis and permanent sterility.

The following section presents a brief overview of fertility control agents commercially available or widely tested on free-living wildlife, zoo animals, and cats and dogs. Taking into account field applications for free-roaming dogs, the review included only those drugs that induce infertility for at least 6 to 12 months after one or two doses. Some examples of contraceptives that are very effective in fully confined companion animals but unlikely to be suitable for dog population management are provided. Unless explicitly mentioned, most of the information on contraceptives for zoo animals was derived from the Association of Zoos and Aquariums Wildlife Contraception Center at the St. Louis Zoo [29], and information on dogs and cats from the Alliance for Contraception in Cats and Dogs [22].

\subsection{Hormonal methods}

Several steroid hormones, such as progestins, estrogens, and androgens, have been used as reproductive inhibitors in dogs, zoo animals, and in some wildlife species. Higher doses of these hormones are required to block ovulation than to achieve contraception; thus, it is possible that ovulation and behavioral signs of estrus occur in animals that are otherwise unable to conceive [22]. Synthetic progestins include megestrol acetate (MA), melengestrol acetate (MGA) and levonorgestrel. MA, used for dogs and cats over several decades under different brand names, prevented estrus in $92 \%$ of bitches when administered orally for 8 days, starting at a very specific time of the estrous cycle (proestrus) [30]. These specific requirements make MA a classic example of a contraceptive that is very effective for confined companion animals but unsuitable for free-roaming dogs. MGA has been widely used in zoo animals and is very effective on many carnivore species, primates, and ungulates. Delivered as an implant, MGA induces infertility for at least 2 years or longer, depending on species. An MGA implant may vary in cost between US\$ 25 and 75, depending on species and body weight [29]. However, MGA is associated with a variety of uterine pathologies and its use is not generally recommended for long-term contraception of canids and felids [27,28,31]. Similarly, synthetic progestins are not recommended for pregnant animals because in some species they may induce embryonic resorption, stillbirth, or abortion [32]. Levonorgestrel is a synthetic progestin used as the active component of a multiyear implant contraceptive originally approved by the US Food and Drug Administration for human contraception and known as Norplant (WyethAyerst) [33]. Because of side effects such as migraine, irregular menstrual cycles, and weight changes, the drug was withdrawn from several markets but is still used for human contraception in others [34]. In animals, levonorgestrel has been used for long-term inhibition of reproduction without apparent adverse side effects. For instance, levonorgestrel implants provided $\geq 3$ to 4 years of contraception in tammar wallabies (Macropus eugenii) [35], gray kangaroos (Macropus giganteus) [36], and koala (Phascolarctos cinereus) females [37]. Levonorgestrel implants induced infertility in captive Cotton-top tamarins (Saguinus oedipus) for 19 to 50 weeks [38] and in domestic cats for at least 1 year [39]. Because the patent on levonorgestrel implants has recently expired, at least in Australia, it is now possible to obtain these products for US\$ 10 per dose (G. Coulson, personal communication), although no trial has been published on effects and effectiveness in dogs.

Other hormonal methods are based on GnRH agonists, which are proteins that mimic GnRH and stimulate production and release of FSH and LH. The treatment with GnRH agonists initially causes estrus and ovulation, also known as the "flare-up" effect, followed by prolonged ovarian quiescence [22,25]. Female dogs treated with a GnRH agonist implant should be considered fertile for the following 3 to 4 weeks $[29,40]$. GnRH agonists also cause a temporary enhancement of testosterone and semen production in males. The effectiveness of the various GnRH agonists depends on many factors, including the agonist potency, the release system, the dose, and the duration of treatment [25]. The side effects of GnRH agonists are generally similar to those associated with removal of the gonads but are reversed once the treatment, often 
delivered as an implant, is suspended. In dogs, GnRH agonists may cause abortion $[33,40]$. Among GnRH agonists, deslorelin (Suprelorin, Virbac), administered as an implant, induced 1 to 2 year contraception in cats and other felids, wild dogs, and tammar wallabies [27,41-43]. In dogs, deslorelin postponed estrus in females for up to 27 months, and the duration of efficacy did not depend on the stage of the estrous cycle of the animal when treated [44]. In males, the suppression of reproduction was dose-related: dogs that received $>0.3 \mathrm{mg} / \mathrm{kg}$ body weight of deslorelin were infertile for at least 12 months and spermatogenesis was suppressed for more than a year in 14 of 16 dogs administered deslorelin [44]. In both sexes, fertility resumed after the implants were removed [44]. Suprelorin is registered for use in male dogs in Australia and Europe; in Europe, the cost of a single 9.4-mg implant to veterinarians is US\$ 100 (M. Brash, personal communication).

The GnRH agonist azagly-nafarelin (Gonazon, Intervet International B.V.), administered as an implant, induced at least 1-year reversible contraception in female dogs and suppressed estrus for 18 months in $92 \%$ of bitches given a second implant [45]. Gonazon prevented puberty in young female dogs for at least 1 year, and suppressed estrus in cats for at least 24 months with no side effects observed [45]. In $81 \%$ of male dogs, Gonazon implants induced a $96 \%$ decrease in the concentration of testosterone for at least 6 months. In parallel, a reduction of aggressive behavior was observed in $62 \%$ of the treated dogs older than 6 years and in $73 \%$ of the treated dogs younger than 3 years [23]. Gonazon received regulatory approval in the EU in 2006, but the company never brought it to market.

\subsection{Immunocontraceptives}

Immunocontraceptive vaccines act by inducing antibody production against proteins or hormones essential for reproduction and thus preventing conception. The immunocontraceptives most commonly used for wildlife are GnRH-based vaccines and ZP-based vaccines. GnRH vaccines target GnRH, thus ultimately preventing ovulation and spermatogenesis; ZP-based vaccines inhibit eggsperm binding and fertilization. The effectiveness and longevity of immunocontraceptive vaccines, as well the incidence and severity of side effects, depend on many factors that include sex, age, and species as well as active ingredients, formulation, and dose of the vaccine and of the adjuvant $[20,46]$. ZP-based vaccines have been used to inhibit reproduction in rodents, ungulates, carnivores, elephants, and marsupials [20,47]. For instance, a single injection of the ZP vaccine SpayVac (ImmunoVaccine Technologies) induced infertility in white-tailed deer and horses for up to 4 years $[46,48]$. Although early trials in dogs were promising [49], ZP-based vaccines did not induce infertility in cats [50] and dogs [51]. Conflicting findings between studies might be due to differences in the methods used to obtain $\mathrm{ZP}$, vaccine formulation, type of adjuvant employed, and to differences in vaccination schedule [24,47]. ZP-based vaccines prevent fertilization but do not affect ovulation; thus, treated animals exhibit estrus, and in some species cycle more frequently than untreated individuals [52,53].
GnRH-based immunocontraceptive vaccines stimulate the production of antibodies that bind to circulating $\mathrm{GnRH}$, thus preventing the release of $\mathrm{LH}$ and FSH. Several GnRHbased immunocontraceptive vaccines have been developed and tested on many species of mammals. The majority of these vaccines have been designed for delivery in multiple doses to livestock and companion animals [20]. Single-dose GnRH-based vaccines, specifically developed for wildlife, have more potential for use in managing dog populations. One of these vaccines, GonaCon, recently registered in the United States as a contraceptive for white-tailed deer, horses, and feral donkeys, induced infertility in wild boar (Sus scrofa), cats, dogs, horses (Equus caballus), bison (Bison bison), and ground squirrels (Spermophilus beecheyi) for at least 1 to 6 years after a single injection [48,54-56]. In cats, GonaCon induced infertility for 1 year in $93 \%$ of the 15 females treated with a single dose; in years 2,3 , and 4 following injection, reproduction was suppressed in $73 \%$, $53 \%$, and $40 \%$ of females, respectively [57]. In dogs, no data are available on the duration of induced infertility. In all species, GonaCon prevents ovulation and treated females do not exhibit estrous behavior [56,57]. The lack of estrous behavior prevents females from attracting males and might result in reduced diseases transmission or bite rates. For instance, in brushtail possums (Trichosurus vulpecula), the transmission coefficient of leptospirosis was $28 \%$ higher in populations subjected to tubal ligation, where animals were hormonally competent and cycling, than in control populations [58]. Similarly, gonadectomy, which has the same effect of GonaCon decreased the leptospirosis transmission rate by $63 \%$ to $88 \%$ in sterilized female and male possums compared with animals in nonsterilized populations [59].

Although in most species GonaCon has no side effects, in others it caused a granuloma (thickened tissue filled with fluid) at the injection site. Two years after vaccination, six of 15 cats had a palpable, nonpainful injection site granuloma [57]. Dogs treated with GonaCon showed sterile abscesses and draining tracts at the injection site relatively soon after injection [60]. Following these findings, a new formulation of GonaCon was produced: the results from a pilot study conducted on captive dogs in Mexico with the new formulation showed no abscess at injection site [61]. Combined rabies and GnRH vaccines have potential for dog rabies control, although the effect and long-term efficacy remain to be tested in dogs [16,62]. GonaCon is not currently commercially available for dogs. However, the US Department of Agriculture Animal and Plant Health Inspection Service is actively seeking a licensing and manufacturing partner (J. Eiseman, personal communication).

\subsection{Chemosterilants}

Several drugs have been developed for the sterilization of male dogs. In particular, intrastesticular sterilants have been studied for more than five decades; these are injected in the testes, epididymis, or vas deferens and cause lack of sperm in semen and thus infertility.

Zinc gluconate neutralized by arginine (Neutersol, Addison Biological Laboratory Inc.) was approved in 2003 by the US Food and Drug Administration for chemical 
sterilization of male puppies. Injected into the testicles, this chemical causes sclerosis of the testes and sterility.

Neutersol induced sterilization in $99.6 \%$ of the 223 male puppies aged 3 to 10 months [63]. Although the treatment with this chemical does not require general anesthesia, sedation is recommended to prevent movements of the dog during injection. Correct injection technique was found critical for the safe use of Neutersol in order to avoid ulceration of the scrotum and painful swelling of the testes. Unlike surgical castration, Neutersol does not involve removal of the testicles so that testosterone is not completely eliminated [28]. In a study carried out in the Galapagos, severe injection-site reactions occurred in 3.9\% of the 103 dogs treated with zinc gluconate; basal testosterone concentration in treated dogs decreased initially but was similar to untreated dogs 2 years after treatment [15]. Thus, secondary male characteristics such as roaming, marking, aggression, or mounting may be displayed.

Zinc gluconate is currently available in Mexico, Colombia, Bolivia, and Panama as Esterilsol and in the United States as Zeuterin (both through Ark Sciences, New York). The cost of Esterisol is about US\$15 per dog (medium size) [22]. A similar formulation has regulatory approval in Brazil as Infertile (Rhobifarma Indústria Farmacêutica). A study carried out with Esterilsol in Mexico found that this compound induced azoospermia (absence of sperm) or aspermia (absence of semen) in 52 of the 53 dogs administered a single dose per testis [64]. Ulcers related to poor injection technique occurred at the injection site in $2.6 \%$ of the dogs; however, their incidence decreased when proper injection technique, such as using new needles for each injection, were employed. A similar study conducted in Brazil [18] in dogs concluded that zinc gluconate could be regarded as a permanent sterilant with no observed sign of behavioral alteration or severe discomfort following intratesticular injection.

Calcium chloride $\left(\mathrm{CaCl}_{2}\right)$, delivered as intratesticular injection, is being researched as a sterilant for dogs. $\mathrm{CaCl}_{2}$ caused atrophy of the seminiferous tubules and decreased testosterone concentration and sperm count in a dosedependent manner [65]. Although $\mathrm{CaCl}_{2}$ did not affect dogs' food intake, chronic stress, or blood parameters, swelling of the testicles persisted for 3 weeks following injection and the behavior of the animals returned to normal (although no definition of normal was provided) a month after treatment [65]. More studies are ongoing to standardize and validate formulation, dosage, and administration protocol for $\mathrm{CaCl}_{2}$ [22]. The low cost, ease of use, and cultural acceptance of a sterilization method that does not require removal of the testes make male sterilants a valuable tool for large-scale sterilization campaigns, particularly in areas lacking clinical facilities or skilled staff $[15,18,28]$.

\subsection{Novel fertility control inhibitors}

A wide spectrum of technologies, ranging from recombinant vaccines to fusion proteins, has been used in various animal species to develop novel immunocontraceptive vaccines that could ultimately also be tested on dogs. For instance, recombinant GnRH-based vaccines have been successful in inducing infertility in male and female cats for at least 20 months after administration of two doses (at 0 and 28 days), with no evidence of tissue or organ damage [66]. Other technologies include attenuated recombinant herpesviruses expressing fertility antigens to induce infertility in dogs and cats, phage-GnRH constructs for immunocontraception of dogs, novel toxin conjugates for sterilization via gonadotroph ablation, bacterial ghosts, and virus-like-particles [22,51,67,68].

\section{Do ownership status and confinement of dogs affect the type of contraceptives and sterilants used? Considerations for field applications}

In most countries, a dog population is composed of animals belonging to all categories, ranging from the two extremes of confined dogs to roaming, ownerless animals. These categories are not fixed, as confined dogs can become roaming dogs and ownerless dogs can be adopted or cared for by one or more person in the community [2,14]. The management of a local population of dogs through fertility control must take into account important differences between dog categories such as natality, mortality, and accessibility. Other differences, such as owner and public expectations on the duration of infertility, the costs of sterilization, and the responsibilities for meeting these costs, will influence the choice of contraceptives and/or sterilants (Table 1 ).

For confined dogs, the ultimate decision regarding sterilization rests with the owner; for free-roaming dogs, the decision rest with the community or even with regional or government authorities committed to decrease the impact of dogs on society. The choice of appropriate fertility inhibitors thus shifts from personal preferences and beliefs

Table 1

Differences in dog categories, defined through dog confinement and ownership status, likely to affect the type of contraceptives or sterilants used on dogs.

\begin{tabular}{|c|c|}
\hline Confined dogs & Free-roaming dogs \\
\hline $\begin{array}{l}\text { Decision to use fertility } \\
\text { inhibitors rests with owner }\end{array}$ & $\begin{array}{l}\text { Decision to use fertility } \\
\text { inhibitors rests with wider } \\
\text { community }\end{array}$ \\
\hline Most are accessible & Some not accessible \\
\hline Confined after treatment & $\begin{array}{l}\text { Mix with other dogs after } \\
\text { treatment }\end{array}$ \\
\hline $\begin{array}{l}\text { Longer lifespan, often better } \\
\text { health }\end{array}$ & $\begin{array}{l}\text { Shorter lifespan, often poorer } \\
\text { health }\end{array}$ \\
\hline Reproduction planned & $\begin{array}{l}\text { Free to reproduce, may be } \\
\text { pregnant when treated with } \\
\text { fertility inhibitor }\end{array}$ \\
\hline $\begin{array}{l}\text { Sterilized to prevent } \\
\text { reproduction or sex-related } \\
\text { behavior, improve health, } \\
\text { and reduce disease risk for } \\
\text { the dog }\end{array}$ & $\begin{array}{l}\text { Sterilized to decrease } \\
\text { population size and control } \\
\text { diseases }\end{array}$ \\
\hline $\begin{array}{l}\text { Cost of sterilization met by } \\
\text { owner }\end{array}$ & $\begin{array}{l}\text { Cost of sterilization rarely met } \\
\text { by owner }\end{array}$ \\
\hline $\begin{array}{l}\text { No or very few side effects of } \\
\text { contraceptive acceptable by } \\
\text { owner on individual dog }\end{array}$ & $\begin{array}{l}\text { Some side effects of } \\
\text { contraceptive acceptable for } \\
\text { population }\end{array}$ \\
\hline $\begin{array}{l}\text { Contraceptives expected } 100 \% \\
\text { effective }\end{array}$ & $\begin{array}{l}\text { Contraceptives not expected } \\
100 \% \text { effective }\end{array}$ \\
\hline $\begin{array}{l}\text { Duration of infertility expected } \\
\text { to be predictable }\end{array}$ & $\begin{array}{l}\text { Duration of infertility may vary } \\
\text { and is evaluated on populations }\end{array}$ \\
\hline
\end{tabular}

The statements are relative and not absolute for each dog category. 
to considerations for a wider context. Confined dogs are, by definition, accessible at all times, unlike free-roaming animals, although not all owners of confined dogs are willing to have their dogs sterilized $[14,15,18]$. For instance, in Sri Lanka, 65\% of the dog owners offered free contraceptives for dogs accepted this method against $18 \%$ that were opposed and 17\% that were undecided [13]; in Samoa, 49\% of dog owners believed sterilization affected dogs' ability to guard [6].

For free-roaming animals, accessibility varies widely and depends on the proportion of individually and community-owned dogs versus the proportion of ownerless dogs.

Continuous access means a dog can be administered multiple doses of a fertility control drug at precise intervals, treatment can be discontinued at any time, and possible side effects can be monitored and treated if necessary. Confinement of dogs is also important for those contraceptives that induce initial ovulation, such as GnRH agonists, or that may cause more frequent cycling such as PZ-based vaccines. Although some confined dogs are kept on a chain in open yards, most confined dogs are kept indoors, with no access to conspecifics. Conversely, roaming dogs treated with ovulation-inducing contraceptives will attract other dogs, potentially increasing risk disease transmission and bite rates.

Confined dogs generally have a relatively long lifespan; conversely, roaming dogs in many parts of the world do not live beyond 2 or 3 years because of malnutrition, diseases, and poor health $[69,70]$. As population turnover of roaming dogs is fast because of high mortality rates, a fertility inhibitor that prevents reproduction for 2 to 3 years is likely to cover the entire lifespan of most animals. Studies in wildlife species indicated that imposed infertility can increase lifespan and improve health, possibly because of the reduced costs of maternal investment $[71,72,73]$. If this was proven in dogs, more long-acting contraceptives or permanent sterilants would be required to counteract the infertility-induced increase in survival.

Owners of confined dogs are generally aware of the reproductive status of their animals so that treatment during pregnancy can be avoided. Conversely, free-roaming dogs may be pregnant when administered fertility inhibitors. Drugs that might induce abortion are thus safer for confined dogs.

Confined dogs are sterilized for preventing reproduction but also for suppressing male sexual behavior such as spraying and roaming and for treating medical conditions such as prostatic hyperplasia and mammary tumors $[22,23]$. Ownerless dogs, as well as many owned roaming dogs, are sterilized during mass campaigns aimed at reducing population size and growth, and at eliminating dog-borne diseases [74,75]. For free-roaming dogs, the costs of surgical sterilization are met by local nongovernmental agencies or public authorities, often as part of mass disease-elimination campaigns. However, the cost of surgical sterilization may prevent these campaigns from being successful $[6,76]$. Mass vaccination and sterilization campaigns aim at reaching thousands or even hundreds of thousands of dogs: if fertility inhibitors are used as alternative to surgical sterilization, the cost of these drugs must be lower than the cost of surgical sterilization, for such a program to be cost-effective [16]. Individual owners are relatively more likely to afford the cost of more expensive contraceptives such as implants of GnRH agonists. For instance, a study conducted in Cambodia [77] found that in urban and periurban areas, $96 \%$ of dog owners were willing to pay for rabies vaccination. In this context, it is possible that, if the cost of sterilization was similar to that of rabies vaccination, owners would be willing to sustain both. However, owners often quote affordability as one of the reasons against sterilization [14]. For instance, in Samoa, $52 \%$ dog owners offered surgical sterilization at costrecovery rates of US\$20 to 40 per dog, quoted cost as a major issue when deciding whether to sterilize dogs [6]. In such context, the proportion of dogs sterilized would increase if fertility inhibitors cheaper than of US\$20 to 40 were available.

Owners that are willing to pay for nonsurgical contraception are likely to expect that the drugs have no side effects, are fully effective, and have a predictable duration so that fertility can be resumed once the contraceptive is removed. Owners are also less likely to tolerate side effects, particularly if the probability of their dog to experience these side effects is unknown.

At population level, the incidence and severity of side effects of any fertility inhibitor should be compared with alternative options [26]. For instance, the probability that a small proportion of animals are likely to experience a temporary discomfort in the injection site, as might be the case for male chemosterilants or immunocontraceptives, should be compared with the incidence of complications associated with surgery. In a wider context, the probability and severity of side effects induced by fertility inhibitors should be considered in relation to a mass campaign's potential impact on diseases such as rabies.

Besides differences between dogs, social and cultural difference must be taken into account when considering both surgical and nonsurgical fertility control to manage dog populations. For instance, in Samoa, 28\% opposed dog sterilization that was perceived to cause laziness, health problems, and reduce dogs' ability to guard; $46 \%$ felt that bitches should either have a litter or go through estrus at least once [6]. In Thailand, $75 \%$ of caretakers of freeroaming dogs said that dog sterilization (not specified whether surgical or nonsurgical) is not consistent with their religious beliefs [14]. Informed decisions on dog population management should be taken by weighing advantages and disadvantages of each fertility inhibitor against what is socially and culturally acceptable.

\section{Conclusions and recommendations}

The use of fertility inhibitors is gaining acceptance to control populations of companion animals and wildlife $[19,21,24]$. For dog population management, nonsurgical sterilization is increasingly advocated as deserving priority for development because of its potential to be more costeffective than surgical sterilization $[15,21,22,78]$. The benefits of using sterilization (both surgical and nonsurgical) alongside vaccination to manage dog populations include the reduction in population turnover, which also results in 
the population maintaining herd immunity, improved health, potential reduction of bite rate, and increased owner compliance as owners bring their dogs to sterilization centers $[4,26,74]$. If sterilization was proven to decrease contact rate and if the latter was directly associated with disease transmission, as found in other species, sterilization would also decrease diseases transmission [58]. Clearly, more research is warranted in this area. In parallel, more studies should assess whether a decrease in dog density is associated with a decrease in bite rates, attacks on livestock, and road traffic accidents.

This review indicated that the past decade saw a significant increase in studies concerning fertility inhibitors for dogs. Despite the fact that several studies mentioned that these drugs could be used to decrease dog population size and impact, very few analyzed how differences in reproduction, survival, and accessibility of dogs, as well as costs and societal expectations, might affect the type of fertility inhibitors to be used in dog population management.

This review further explored these differences and their relevance for mass dog sterilizations aimed at reducing dog numbers or dog impact such bite rates or diseases. To be used in roaming dogs during mass sterilizations campaigns, fertility inhibitors should 1 ) be effective when administered in one dose or in booster doses, the latter delivered in conjunction with other drugs such as rabies vaccines; 2) render the majority of animals infertile for 1 or more years; 3 ) have zero or acceptable side effects, with known incidence and severity; 4) be safe for administration during pregnancy; 5 ) be relatively inexpensive, particularly in comparison to surgical sterilization; 6) inhibit female reproduction, but

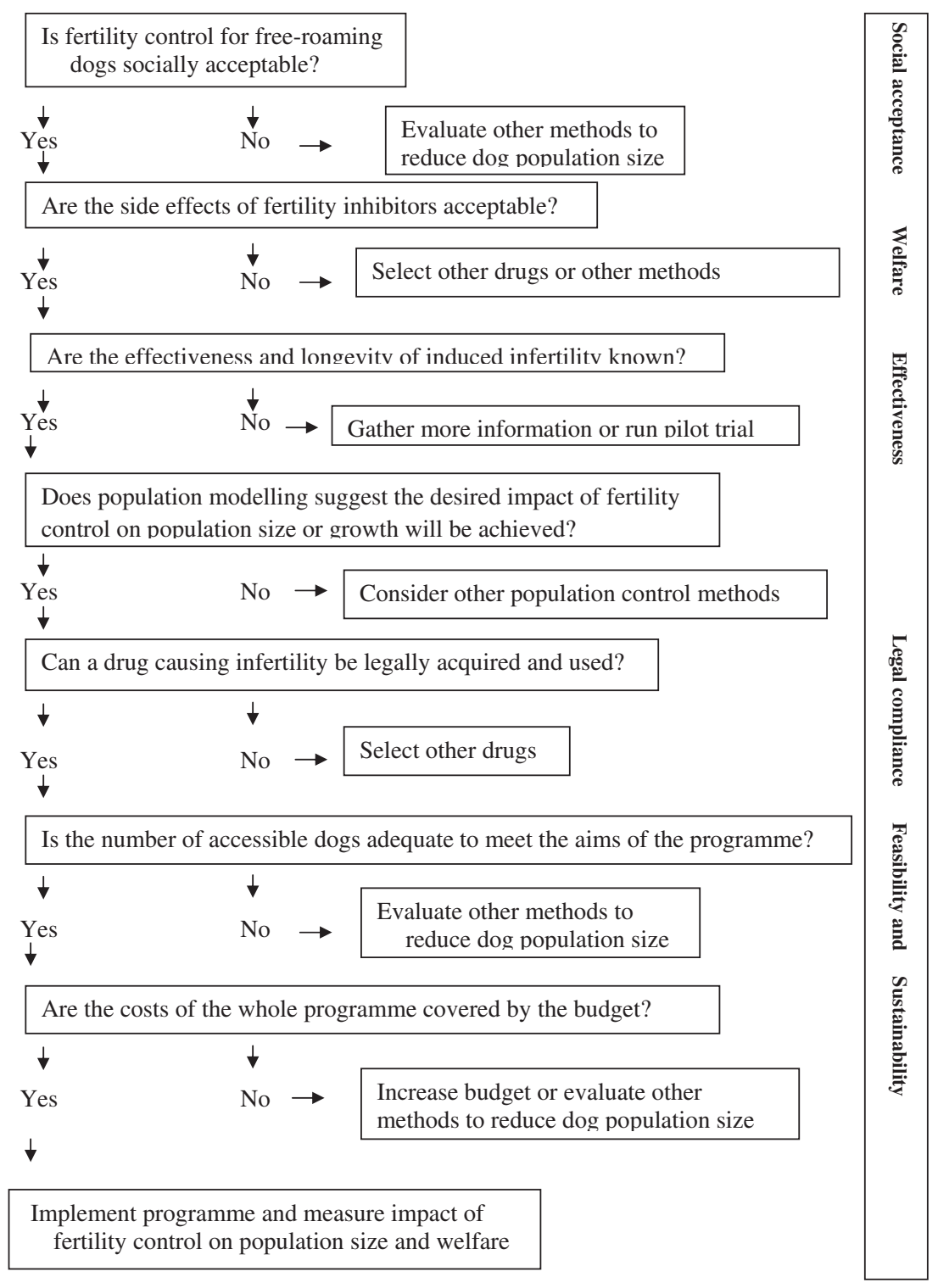

Fig. 2. Decision tree and criteria to evaluate the use of nonsurgical fertility control in dog population management. The decision tree assumes that fertility control has been selected as the best option, among others available, for managing dog populations. 
ideally prevent reproduction in both sexes; and 7) be stable under a wide range of field conditions.

The overview of fertility inhibitors commercially available or widely tested in other animal species suggested that some meet most of the above criteria and therefore have potential for large dog sterilization campaigns. For instance, immunocontraceptives and male sterilants deserve further attention for dog population management. Although females are the primary target to manage populations through fertility control, male sterilants could also be employed, particularly if less expensive or with longer effectiveness than those used on females. The review indicated that contraceptives such as synthetic progestins and GnRH agonists are more likely to remain limited to confined dogs, partly because of costs, but also because of the induction of ovulation that, in roaming dogs, might cause an initial increase of contact rate with potential increased risk of disease transmission. The review also showed the relative lack of knowledge on the impact of fertility inhibitors on behavior and on sexually immature versus pubertal dogs and suggested that more work is required in this area.

Besides the effects of fertility inhibitors on individual animals, the impact of fertility control to manage dog populations have been rarely measured. Notable exceptions are surgical sterilization campaigns carried out in India that resulted in sterilization of $62 \%$ to $86 \%$ freeroaming dogs $[75,79]$.

If nonsurgical fertility control is chosen to manage dog populations or their impact, social acceptance, humaneness, effectiveness, feasibility, costs, and sustainability of this method should be evaluated at an early planning stage (Fig. 2). For instance, owners of roaming dogs as well as other stakeholders should be consulted and informed on the possible benefits of fertility control. Once verified that dogs are locally considered as overabundant, the decision tree in Figure 2 could be used for the steps that must be taken before launching a mass sterilization campaign. This framework is based on the assumption that a set reduction of dog population size, or the elimination of a disease such as rabies, within a predefined timeframe can be achieved by using nonsurgical fertility control as an additional tool to education and vaccination. If fertility control is regarded as a socially acceptable option for dog population management, the welfare (i.e., side effects), long-term effectiveness, and effects of fertility inhibitors used must be carefully evaluated. Decisions should be based on available data or on pilot trials with dogs that are regularly monitored and have access to veterinary care.

Knowledge of the local dog population dynamics can be based on household surveys carried out in conjunction with estimates of roaming dogs and on data collected on natality and survival of the different categories of dogs. The latter can be used to model the impact of fertility control on population dynamics. In wildlife management, models are increasingly used to investigate the effects of contraception on population size [80-83]; these models could be adapted for dog management.

Legal requirement on the import and use of a particular drug should be considered, unless the drug is already licensed for use on dogs in that country [19]. Legal requirements vary widely between countries: if a drug is not available in a particular country, it might take months or years before the authorities approve its use. In parallel, the whole feasibility of the campaign must be carefully evaluated. This concerns the practicalities of delivering fertility inhibitors to a sufficient proportion of dogs, the actual cost of fertility inhibitors, staff, vehicles, and consumables as well as the sustainability of the campaign. "Sustainability" can be defined as the ability of achieving the aim of the campaign (e.g., a set reduction of dog numbers, dog bites or traffic incidents, elimination of a disease) within a set time, resources, and budget. The campaign can start only once all these steps have been carefully considered.

The development of safe and effective fertility inhibitors for dogs discussed in this review must also be matched by evidence that nonsurgical fertility control is an efficient, humane, and socially acceptable alternative to surgical sterilization for managing overabundant populations of dogs and their impact on human interests. Understanding how different dog categories require different fertility inhibitors is only one of the many steps that will lead to largescale applications of these methods. Integrating fertility control with vaccination and public education programs, registering new drugs for dogs, and evaluating the feasibility, effectiveness, sustainability, and impact of mass nonsurgical sterilization campaigns are the main challenges for the future of dog population management.

\section{Acknowledgments}

The authors thank Kathleen Fagerstone, Amy Fisher, and Joyce Briggs for their comments and suggestions that increased the clarity and focus of the manuscript and Doug Eckery and John Eisemann for technical advice.

\section{References}

[1] Hughes J, Macdonald DW. A review of the interactions between free-roaming domestic dogs and wildlife. Biol Conserv 2013;157: 341-51.

[2] International Companion Animal Management Coalition. 2007. Humane dog population management guidance. http://icamcoalition.org/ Accessed October 23, 2012.

[3] Macpherson CNL, Meslin FX, Wandeler AI. Dogs, zoonoses and public health. Second edition. Wallingford, UK: CABI International; 2013.

[4] Jackman J, Rowan A. Free-roaming dogs in developing countries: the public health and animal welfare benefits of capture, neuter, and return programs. In: Salem D, Rowan A, editors. State of the animals. Washington DC: Humane Society Press; 2007. p. 55-78.

[5] Rosado B, García-Belenguer S, León M, Palacio J. A comprehensive study of dog bites in Spain, 1995-2004. Vet J 2009;179:383-91.

[6] Farnworth MJ, Blaszak KA, Hiby EF, Waran NK. Incidence of dog bites and public attitudes towards dog care and management in Samoa. Anim Welfare 2012;21:477-8.

[7] Beck AM. The human-dog relationship: a tale of two species. In: Macpherson CNL, Meslin FX, Wandeler AI, editors. Dogs, zoonoses and public health. Wallingford, UK: CABI International; 2013. p. $1-12$.

[8] Sudarshan MK, Mahendra BJ, Narayan DH. A community survey of dog bites, anti-rabies treatment, rabies and dog population management in Bangalore city. J Comm Dis 2001;33:245-51.

[9] Knobel DL, Cleaveland S, Coleman PG, Fèvre EM, Meltzer MI, Miranda ME, et al. Re-evaluating the burden of rabies in Africa and Asia. Bull WHO 2005;83:360-8. 
[10] Young JK, Olson KA, Reading RP, Amgalanbaatar S, Berger J. Is wildlife going to the dogs? The impact of feral and free-roaming dogs on wildlife populations. BioScience 2011;61:125-32.

[11] Hiby E. Dog population management. In: Macpherson CNL Meslin FX, Wandeler AI, editors. Dogs, zoonoses and public health. Wallingford, UK: CABI International; 2013. p. 177-204.

[12] Lembo T, Craig PS, Miles MA, Hampson KR, Meslin F-X. Zoonoses prevention control and elimination in dogs. In: Macpherson CNL Meslin FX, Wandeler AI, editors. Dogs, zoonoses and public health. Wallingford, UK: CABI International; 2013. p. 205-258.

[13] Matibag GC, Ohbayashi Y, Kanda K, Yamashina H, Kumara B, Gamini Perera IN, et al. A pilot study on the usefulness of information and education campaign materials in enhancing the knowledge, attitude and practice on rabies in rural Sri Lanka. J Infect Developing Countries 2009;3:55-64.

[14] Toukhsati SR, Phillips CJC, Podberscek AL, Coleman GJ. Semiownership and sterilisation of cats and dogs in Thailand. Animals 2012;2:611-27.

[15] Levy JK, Crawford PC, Appel LD, Clifford EL. Comparison of intratesticular injection of zinc gluconate versus surgical castration to sterilize male dogs. Am J Vet Res 2008;69:140-3.

[16] Massei G, Miller LA, Killian GJ. Immunocontraception to control rabies in dog populations. Human-Wildlife Interactions 2010;4:155-7.

[17] Massei G. Catch, inject and release: immunocontraception as an alternative to culling and surgical sterilization to control rabies in free-roaming dogs. In: Fooks AR, Müller T, editors. Rabies control-towards sustainable prevention at the source. Compendium of the OIE Global Conference on Rabies Control, Incheon, 2012. Paris, France: OIE Publishing; 2013. p. 181-7.

[18] Soto FR, Viana WG, Mucciolo GC, Hosomi FY, Vannucchi CI, Mazzei CP, et al. Evaluation of efficacy and safety of zinc gluconate associated with dimethyl sulphoxide for sexually mature canine males chemical neutering. Reprod Dom Anim 2009;44:927-31.

[19] Fagerstone KA, Miller LA, Killian GJ, Yoder CA. Review of issues concerning the use of reproductive inhibitors, with particular emphasis on resolving human-wildlife conflicts in North America. Integrat Zool 2010;5:15-30.

[20] McLaughlin EA, Aitken RJ. Is there a role for immunocontraception? Moll Cell Endocrynol 2011;335:78-88.

[21] Munks MW. Progress in development of immunocontraceptive vaccines for permanent non-surgical sterilization of cats and dogs. Reprod Dom Anim 2012;47:223-7.

[22] Alliance for Contraception in Cats and Dogs (ACC\&D). Contraception and fertility control in dogs and cats. E-book: 2013.

[23] Goericke-Pesch S, Wilhelm E, Ludwig C, Desmoulins PO, Driancourt MA, Hoffmann B. Evaluation of the clinical efficacy of Gonazon implants in the treatment of reproductive pathologies, behavioral problems, and suppression of reproductive function in the male dog. Theriogenology 2010;73:920-6.

[24] Levy JK. Contraceptive vaccines for the humane control of community cat populations. Am J Reprod Immunol 2011;66:63-70.

[25] Gobello C. New GnRH analogs in canine reproduction. Anim Reprod Sci 2007;100:1-13.

[26] Massei G. Non-surgical contraception and sterilisation for dogs. In: Macpherson CNL, Meslin FX, Wandeler AI, editors. Dogs, zoonoses and public health. Wallingford, UK: CABI International; 2013. p. 259-70.

[27] Munson L. Contraception in felids. Theriogenology 2006;66:126-34.

[28] Kutzler M, Wood A. Non-surgical methods of contraception and sterilization. Theriogenology 2006;66:514-25.

[29] Association of Zoos \& Aquariums (AZA) Wildlife Contraception Center, St Louis Zoo http://www.stlzoo.org/animals scienceresearch/contraceptioncenter/contraceptionrecommendatio/ contraceptionmethods. Accessed October 23, 2012.

[30] Burke TJ, Reynolds HA. Megestrol acetate for estrus postponement in the bitch. J Am Vet Med Assoc 1975;167:285-7.

[31] Moresco A, Munson L, Gardner IA. Naturally occurring and melengestrol acetate-associated reproductive tract lesions in zoo canids. Vet Pathol 2009;46:1117-28.

[32] Asa CS, Porton IJ. Wildlife contraception: issues, methods and applications. Baltimore, MD: Johns Hopkins University Press; 2005.

[33] Brache V, Alvarez-Sanchez F, Faundes A, Tejada AS, Cochon L. Ovarian endocrine function through five years of continuous treatment with Norplant subdermal contraceptive implants. Contraception 1990;41:169-77.

[34] Benfield N, Darney PD. Contraceptive implants. In: Shoupe D, editor Contraception. Oxford, UK: Wiley-Blackwell; 2011.

[35] Nave CD, Coulson G, Short RV, Poiani A, Shaw G, Renfree MB. Longterm fertility control in the kangaroo and the wallaby using levonorgestrel implants. Reproduction 2002;60:71-80.
[36] Coulson G, Nave CD, Shaw J, Renfree MB. Long-term efficacy of levonorgestrel implants for fertility control of eastern grey kangaroos (Macropus giganteus). Wildl Res 2008;35:520-4.

[37] Middleton D, Walters B, Menkhorst P, Wright P. Fertility control in the koala, Phascolarctos cinereus: the impact of slow-release implants containing levonorgestrel or oestradiol on the production of pouch young. Wildl Res 2003;30:207-12.

[38] Wheaton CJ, Savage A, Shukla A, Neiffer D, Qu W, Sun Y, et al. The use of long acting subcutaneous levonorgestrel (LNG) gel depot as an effective contraceptive option for cotton-top tamarins (Saguinus oedipus). Zoo Biol 2011;30:498-522.

[39] Baldwin C], Peter AT, Bosu WT, Dubielzig RR. The contraceptive effects of levonorgestrel in the domestic cat. Lab Anim Sci 1994;44:261-9.

[40] Ponglowhapan S. Clinical applications of GnRH agonist deslorelin in dogs and cats. Thai J Vet Med Suppl 2011;41:59-63.

[41] Munson L, Bauman JE, Asa CS, Jochle W, Trigg TE. Efficacy of the $\mathrm{GnRH}$ analogue deslorelin for suppression of oestrous cycles in cats. J Reprod Fertil 2001;57:269-73.

[42] Bertschinger HJ, Trigg TE, Jöchle W, Human A. Induction of contraception in some African wild carnivores by downregulation of $\mathrm{LH}$ and FSH secretion using the GnRH analogue deslorelin. Reproduction 2002;60:41-2.

[43] Herbert CA, Trigg TE. Applications of GnRH in the control and management of fertility in female animals. Anim Reprod Sci 2005 88:141-53.

[44] Trigg TE, Wright PJ, Armour AF, Williamson PE, Junaidi A, Martin GB, et al. Use of a GnRH analogue implant to produce reversible longterm suppression of reproductive function in male and female domestic dogs. J Reprod Fertil Suppl 2001;57:255-61.

[45] Rubion S, Desmoulins PO, Rivière-Godet E, Kinziger M, Salavert F, Rutten F, et al. Treatment with a subcutaneous GnRH agonist containing controlled release device reversibly prevents puberty in bitches. Theriogenology 2006;66:1651-4.

[46] Miller LA, Fagerstone KA, Wagner DC, Killian GJ. Factors contributing to the success of a single-shot, multiyear PZP immunocontraceptive vaccine for white-tailed deer. Human-Wildlife Conflicts 2009;3:103-15.

[47] Kirkpatrick JF, Lyda RO, Frank KM. Contraceptive vaccines for wildlife: a review. Am J Reprod Immunol 2011;66:40-50.

[48] Killian G, Thain DS, Diehl N, Rhyan J, Miller LA. Four-year contraception rates of mares treated with single-injection porcine zona pellucid and GnRH vaccines and intrauterine devices. Wildl Res 2008;35:531-9.

[49] Mahi-Brown CA, Yanagimachi R, Hoffman JC, Huang TT. Fertility control in the bitch by active immunization with porcine zonae pellucidae: use of different adjuvants and patterns of estradiol and progesterone levels in estrous cycles. Biol Reprod 1985;32:76172 .

[50] Levy JK, Mansour M, Crawford PC, Pohajdak B, Brown RG. Survey of zona pellucida antigens for immunocontraception in cats. Theriogenology 2005;62:1334-41.

[51] Gupta SK, Srinivasan VA, Suman P, Rajan S, Nagendrakumar SB, Gupta N, et al. Contraceptive Vaccines based on the zona pellucida glycoproteins for dogs and other wildlife population management. Am J Reprod Immunol 2011;66:51-62.

[52] Nuñez CMV, Adelman JS. Rubenstein DI immunocontraception in wild horses (Equus caballus) extends reproductive cycling beyond the normal breeding season. PLoS ONE 2010;5:e13635.

[53] Gray M, Thain DS, Cameron EZ, Miller LA. Multi-year fertility reduction in free-roaming feral horses with single-injection immunocontraceptive formulations. Wildl Res 2010;37:475-81.

[54] Miller LA, Gionfriddo JP, Fagerstone KA, Rhyan JC, Killian GJ. The single-shot $\mathrm{GnRH}$ immunocontraceptive vaccine (GonaCon ${ }^{\mathrm{TM}}$ ) in white-tailed deer: comparison of several GnRH preparations. Am J Reprod Immunol 2008;60:214-23.

[55] Massei G, Cowan DP, Coats J, Bellamy F, Quy R, Brash M, et al. Longterm effects of immunocontraception on wild boar fertility, physiology and behaviour. Wildl Res 2012;39:378-85.

[56] Massei G, Cowan DP, Coats J, Gladwell F, Lane JE, Miller LA. Effect of the $\mathrm{GnRH}$ vaccine GonaCon ${ }^{\mathrm{TM}}$ on the fertility, physiology and behaviour of wild boar. Wildl Res 2008;35:1-8.

[57] Levy JK, Friary JA, Miller LA, Tucker SJ, Fagerstone KA. Long-term fertility control in female cats with GonaCon ${ }^{\mathrm{TM}}$, a GnRH immunocontraceptive. Theriogenology 2011;76:1517-25.

[58] Caley P, Ramsey D. Estimating disease transmission in wildlife, with emphasis on leptospirosis and bovine tuberculosis in possums, and effects of fertility control. J Appl Ecol 2001;38:1362-70.

[59] Ramsey D. Effects of fertility control on behavior and disease transmission in brushtail possums. J Wildl Manage 2007;71:109-16. 
[60] Griffin B, Baker H, Welles E, Miller LA, Fagerstone KA. Response of dogs to a GnRH-KLH conjugate contraceptive vaccine adjuvanted with Adjuvac $®$. In: Proceedings of the 2nd ACC\&D International Symposium on Nonsurgical Methods for Pet Population Control; 2004. http://www.acc-d.org/ACCD\%20Symposia Accessed 23 October 2012

[61] Vargas-Pino F, Gutiérrez-Cedillo V, Canales-Vargas EJ, Jorge F, Fuentes I, Gress-Ortega LR, et al. Concomitant administration of GonaCon $^{\mathrm{TM}}$ and rabies vaccine in female dogs (Canis familiaris) in Mexico. Vaccine 2013;july 16.

[62] Wu X, Franka R, Svoboda P, Pohl J, Rupprecht CE. Development of combined vaccines for rabies and immunocontraception. Vaccine 2009;27:7202-9.

[63] Wang M. Neutersol: intratesticular injection induces sterility in dogs. In: Proceedings of the 1st ACC\&D International Symposium on Non-Surgical Methods of Pet Population Control; 2002. http://www.acc-d.org/ACCD\%20Symposia Accessed 23 October 2012.

[64] Esquivel LaCroix C. Evaluation of a single intratesticular injection of zinc gluconate neutralized by Arginine (Neutersol ${ }^{\circledR}$ ) as a chemical sterilant in sexually mature, male dogs. In: Proceedings of the 3rd ACC\&D International Symposium on Non-surgical contraceptive methods for Pet Population Control; 2006. http://www.acc-d.org ACCD\%20Symposia Accessed 23 October 2012.

[65] Jana K, Samanta PK. Sterilization of male stray dogs with a single intratesticular injection of calcium chloride: a dose-dependent study. Contraception 2007;75:390-400.

[66] Robbins SC, Jelinski MD, Stotish RL. Assessment of the immunological and biological efficacy of two different doses of a recombinant GnRH vaccine in domestic male and female cats (Felis catus). J Reprod Immunol 2004;64:107-19.

[67] Cui X, Duckworth JA, Lubitz P, Molinia FC, Haller C, Lubitz W, et al. Humoral immune responses in brushtail possums (Trichosurus vulpecula) induced by bacterial ghosts expressing possum zona pellucida 3 protein. Vaccine 2010;28:4268-74.

[68] Cross ML, Zheng T, Duckworth JA, Cowan PE. Could recombinant technology facilitate the realisation of a fertility-control vaccine for possums? NZ J Zool 2011;38:91-111.

[69] Reece JF, Chawla SK, Hiby EF, Hiby LR. Fecundity and longevity of roaming dogs in Jaipur, India. BMC Vet Res 2008;4:1-7.

[70] Hampson K, Dushoff J, Cleaveland S, Haydon DT, Kaare M, Packer C, et al. Transmission dynamics and prospects for the elimination of canine rabies, 2009 transmission dynamics and prospects for the elimination of canine rabies. PLoS Biol 2009;7: e1000053.

[71] Twigg LE, Lowe TJ, Martin GR, Wheeler AG, Gray GS, Griffin SL, et al. Effects of surgically imposed sterility on free-ranging rabbit populations. J Appl Ecol 2000;37:16-39.

[72] Turner A, Kirkpatrick JF. Effects of immunocontraception on population, longevity and body condition in wild mares Equus caballus. Reprod Suppl 2002;60:187-95.

[73] Kirkpatrick JF, Turner A. Achieving population goals in long-lived wildlife with contraception. Wildl Res 2008;35:513-9.

[74] Hiby E. Understanding the need: dog and cat reproduction control around the world. In: 4th ACC\&D International Symposium on Non-Surgical Contraceptive Methods of Pet Population Control; 2010. http://www.acc-d.org/ACCD\%20Symposia Accessed 23rd October 2012.

[75] Totton SC, Wandeler AI, Zinsstag J, Bauch CT, Ribble CS, Rosatte RC, et al. Stray dog population demographics in Jodhpur, India following a population control/rabies vaccination program. Prev Vet Med 2010;97:51-77.

[76] Kasempimolporn S. Moving towards the elimination of rabies in Thailand. J Med Assoc Thai 2008;3:433-7.

[77] Lunney M, Fèvre JS, Stiles E, Ly S, San S, Vong S. Knowledge, attitudes and practices of rabies prevention and dog bite injuries in urban and peri-urban provinces in Cambodia. Int Health 2009;4:4-9.

[78] Carroll MJ, Singer A, Smith GC, Cowan DP, Massei G. The use of immuno-contraception to improve rabies eradication in urban dog populations. Wildl Res 2010;37:676-87.

[79] Reece JF, Chawla SK. Control of rabies in Jaipur, India, by the sterilisation and vaccination of neighbourhood dogs. Vet Rec 2006;159: 379-83.

[80] Rutberg AT, Naugle RE. Population effects of immunocontraception in white-tailed deer Odocoileus virginianus. Wildl Res 2008;35: 494-501.

[81] Druce HC, Mackey RL, Slowtow R. How immunocontraception can contribute to elephant management in small, enclosed reserves: Munyawana population. PLoS one 2011;6:1-10.

[82] Hobbs NT, Bowden DC, Baker DL. Effects of fertility control on populations of ungulates: General, stage-structured models. J Wild Manage 2000;64:473-91.

[83] Kirkpatrick JF, Turner A. Achieving population goals in long-lived wildlife with contraception. Wildl Res 2008;35:513-9. 